\title{
Creating value in firms at different management levels
}

\author{
Roeland van Straten
}

\begin{abstract}
Purpose - Value is created for firms' owners when profits outweigh investments over a given time period. This paper aims to distinguish where, within firms, strategic thinking is required for the purposes of creating value.

Design/methodology/approach - A novel framework is developed, which explains how six sources of value can be identified and logically related to six practical value management levels.

Findings - Importantly, only one source of value, namely, autonomous revenue growth, demands true strategic thinking because it represents an unknown outcome from the strategist's perspective. This source of value can be tapped into at any decision-making level.

Originality/value - This paper clarifies and emphasises that demonstrating strategic wisdom is possible for anyone within a firm and ultimately, it resolves down to the thinking and decision making that increases the chances of generating higher, earlier and more frequent future incoming cash flows.
\end{abstract}

Keywords Cash flows, Profit, Revenue growth, Strategy, Uncertainty, Value

Paper type Research paper

\section{Introduction}

In this paper, it is posited that there are sources of value for firms at each decision making level. However, it is also proposed that only one source of value, namely, autonomous revenue growth, demands true strategic thinking because it represents an unknown outcome from the strategist's perspective. This is because the inherent uncertainty that warrants all true strategic thinking ultimately relates to cash flow uncertainty.[1] By providing an answer to the question of how value creation depends on decision making, in what follows the aim is to increase the chances of strategic wisdom being demonstrated. As such this paper contrasts with and departs from extant strategy frameworks like Porter's five forces model (Porter, 1989, 2008) by offering directly actionable guidance for the purpose of optimising firm-level outcomes.

The article is structured as follows. Section 2 provides background information concerning value creation. Section 3 delineates and describes a novel framework for understanding and maximising value creation in practice where different sources of value are available at different value management levels. Finally, Section 4 concludes.

\section{Background: understanding value creation}

As a general rule, the creation of financial value is central to firms' decision making, subject to different legal, social and environmental responsibilities pursuant of fair prices (Anbarci and Feltovich, 2017; Piron and Fernandez, 1995), sustainable development (Kim et al., 2017; Van Zanten and Van Tulder, 2018) and other objectives. When this is acknowledged along with a recognition that a firm constitutes a complex adaptive system (Bettis and Prahalad, 1995; Fowler, 2003), it can understand why endeavours to statistically relate a
Roeland van Straten is based at the Department of Managerial and Behavioral Sciences, Universiteit Twente, Enschede, The Netherlands.

Received 17 December 2018

Revised 10 July 2019

27 August 2019

Accepted 28 August 2019

(c) Roeland van Straten. Published by Emerald Publishing Limited. This article is published under the Creative Commons Attribution (CC BY 4.0) licence. Anyone may reproduce, distribute, translate and create derivative works of this article (for both commercial and non-commercial purposes) subject to full attribution to the original publication and authors. The full terms of this licence may be seen at http:// creativecommons.org/licences/ by/4.0/legalcode. 
firm's practices to performance may be inherently misguided and illusory (Jarzabkowski et al., 2016). This is because the chain of causality between practices and performance is too long and dependent and independent variables are not entirely separable. As a consequence, direct empirical associations of resources with superior financial performance do not preclude "omission or misspecification of links in the complex causal chain, such as industrial conditions, resource properties, competitive advantage or superior performance" (Durand and Vaara, 2009, p. 1247). Understanding value creation also means that to simply equate organisational strategy with organisational performance is incorrect as well. Taking such a stance would discount the unintended consequences of strategic decisions, as well as of the role of luck and unpredictability in value creation (Mantere, 2013).

It should be emphasised that from the perspective of a firm's viability, the act of creating value is not optional, but always necessary and ongoing, to be measured over time. This means that strategic thinking - given that its goal is to ultimately create value - should be an endless process of striving to attain and maintain a thorough understanding of the relative position of a firm. In this, the strategist should adopt an analytical perspective in which it is neither about a firm pursuing the "right" course of action (because such a thing can never be objectively established) nor about the solving of "problems". As Schön (1991, p. 40) remarks, by emphasising too much on problem-solving, problem settings can end up being neglected, being "the process by which we define the decision to be made, the ends to be achieved, the means which may be chosen". The reality is that in practice, problems do not present themselves as given. Therefore, the strategist must realise that everything "depends" and that strategic thinking and acting is usually much more about improvement than about optimisation (Bettis and Prahalad, 1995).

However, notwithstanding this complexity, the key tenet of this paper is that a paradox exists from the perspective of strategic thinking and more specifically, what can reasonably be classed as representing known and unknown outcomes from the strategist's perspective.

Even though the extant literature has been notably silent on this issue of identifying the specific role and focus of strategic decision making in firms, it is nonetheless enshrined in core assumptions underlying the neoclassical economics framework, albeit implicitly and using different terminology (Table I).

Needless to say, there is a burgeoning literature on the extent to which these assumptions are manifest in practice, as well as the theoretical and empirical consequences of deviations from these assumptions. However, if strategic decision making is carried out appropriately as detailed herein, and thus, in accordance with the assumptions in Table I, that will increase the extent to which allocative efficiencies are realised in practise, notwithstanding market failures, which hamper the convergence of private and social optima even where well-intentioned policy interventions are instituted (Kline and Moretti, 2014; Kydland and Prescott, 1977).

Table I Strategic decision making and core neoclassical economic assumptions

Actions occur on the basis of full and relevant information (Lah You cannot optimise value creation via strategic decision making unless et al., 2016) you know how to do so

Utility/profit maximisation (Boland, 1981)

You cannot optimise value creation via strategic decision making unless your goal is to maximise profits

Rationality of preferences (Liu et al., 2006)

You cannot optimise value creation via strategic decision making unless you desire to learn how to do so because you desire to maximise profits 


\section{Creating value at different management levels: a novel framework 3.1 Six value management levels}

The framework that follows is based on the author's knowledge and experience garnered through 20 years of working, researching and teaching in the strategy domain. On the one hand, in methodological terms, the framework is the result of an approach, which combines elements of autoethnography (Adams, 2017; Doloriert and Sambrook, 2011; Kempster and Stewart, 2010) and research as praxis (Lather, 1986). On the other hand, in theoretical terms, the model can be conceived as being derived using systems theory (Cosenz and Noto, 2016; Liedtka, 1998) and more specifically, it rests upon the realisation of five axioms:

1. A firm is a socially constructed, complex and adaptive system;

2. To survive, a firm must be successful in creating value;

3. The goal of strategic thinking is to be prepared for decision making;

4. The probability of success can be increased through better knowledge; and

5. Beliefs cannot be accepted as knowledge unless they are logically true and justified.

First and foremost, it is surely a truism that value is created for the firm's owner when profits outweigh investments over a given time period. This time period needs to be as long as possible to understand if value is being created in the long-run as opposed to short-run value creation, which is subsequently destroyed.

To be effective, strategists need to have enough technical knowledge of value creation when engaging in tacit and explicit strategic analyses. Ideally, this means the strategist has a complete end-to-end understanding of how financial value creation "works", and how it is measured by the overall return on investment (ROI). Fortunately, unlike the much more tacit knowledge that comes from, for example, improving thinking skills, knowledge of different sources of value and salient decision making levels is formal and explicit, and as such it can be codified, taught and learned.

Ultimately, the ongoing activity of value creation requires that the relation between outgoing and incoming cash flows is managed. At the same time, there are in fact multiple "sources" of value, which can be identified when it comes to actual decision making practices. Next, to this, it is also important to discern different "value management" levels because which of these sources of value are accessible is dependent on the level at which the decision maker operates. The lower the level, the less control the decision maker has over the factors that define whether the value is or can be created. Logically, the higher up in the organisation, the more control can be executed, and the more sources of value become available. As will be explained, any final conclusion regarding the creation of value can only be drawn at the highest value management level.

Based on the foregoing, this article argues that the following value management levels, financial metrics and sources of value must be discerned to gain a thorough understanding of value creation (Figure 1, from left to right, per column):

- six "value management" levels;

- the bottom line financial metric per level that relates to the value calculation;

- the legal/organisational context of the level;

- the calculation of the bottom line metric and how it relates mathematically to the bottom line metrics of higher and lower value management levels; and

- the source of value than can be accessed at each level. 


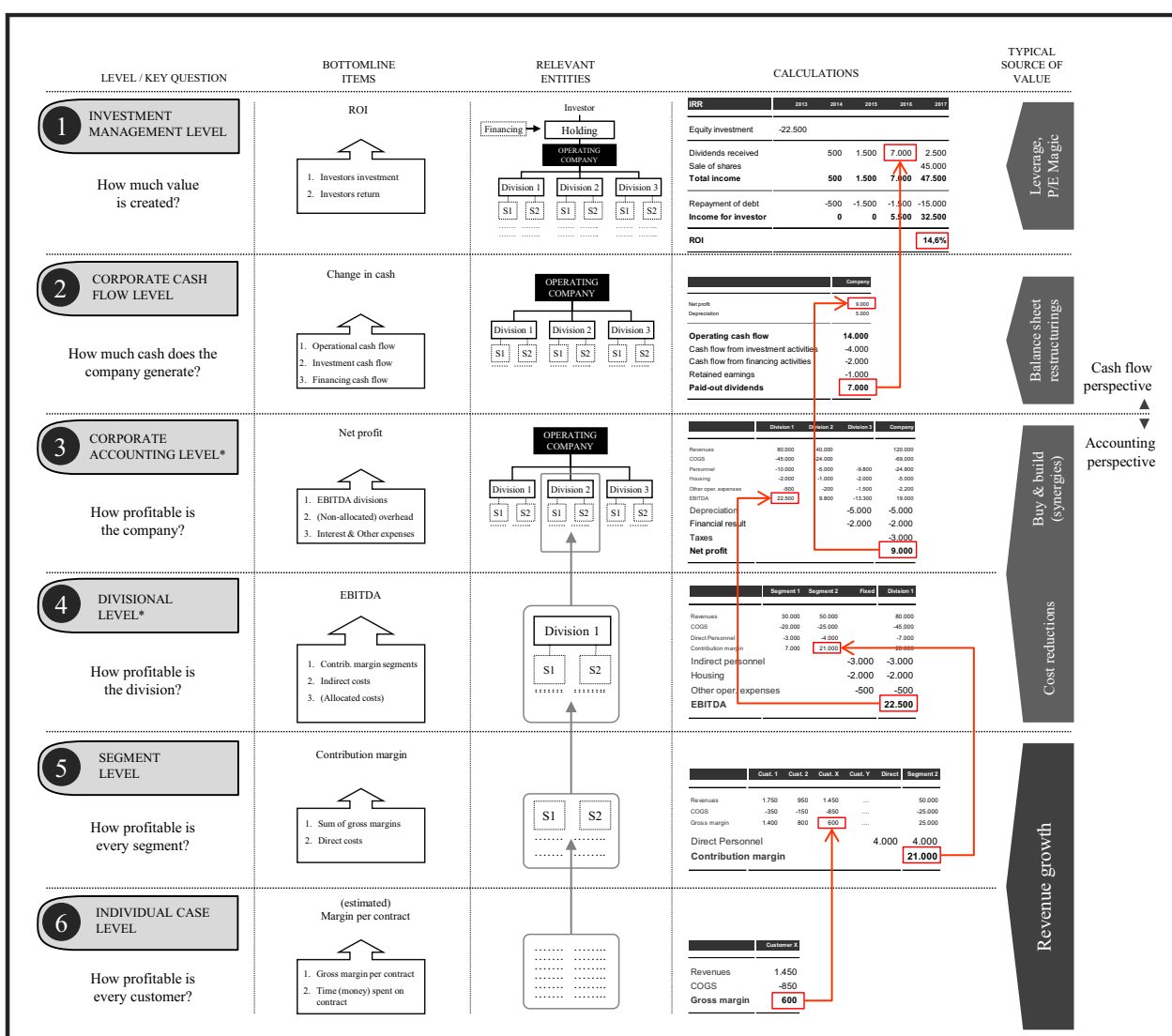

Notes: SME companies are typically one-divisional, merging level 3 and 4 into one level. Within large companies divisions tend to operate like independent companies

The mathematical link between the levels is illustrated in the fourth column of Figure 1. Moving up means elements are added to calculate the upper level's relevant bottom line metric (more information is included). Moving down means elements are eliminated from the upper level's bottom line metric (less information is included). Consequently, the lower the value management level, the more any reference to "value" can be mediated by actions that impact cash flows but are beyond the control of the lower-level decision maker.

\subsection{The accounting versus the cash flow perspective}

When considering the value management levels, it is important to know at what level the management accounting perspective turns into a cash flow perspective. As can be seen in Figure 1, levels three through six focus on management accounting metrics such as revenues, costs and profits, whereas the first and second levels represent the cash flow perspective that focuses only on incoming and outgoing cash flows. Hence, the bottom line metrics of the two top levels are directly included in the value calculation and the bottom line metrics of levels three through six are only indicators of the cash flow items that are needed to make that calculation. For example, when used appropriately, incremental (absolute) gross margin should contribute to the creation of value, assuming both the revenues and costs of goods sold are collected and paid, respectively. Logically, the 
bottom line metrics of levels three through six are all part of a firm's profit and loss statement, while at the second level elements are added that change this overview into a statement of cash flows.

It is also important to consider and understand what a decision maker at a particular level can purposefully do in terms of creating value. As an example, imagine that a manager at the "divisional" level (see level four in Figure 1) states that he or she wants to create value. It is important to emphasise that divisional managers do not control all elements that influence value creation. The best he or she can do is increase earnings before interest taxes depreciation and amortisation (EBITDA). EBITDA is the best indicator of the cash flows that result from decisions made at this divisional level. It remains an indicator of generated cash flows because the actual cash flows that correspond with revenues and costs are not considered in EBITDA calculations. Logically, the divisional manager can essentially ignore any investments and debt or equity financing associated with growing EBITDA, even though these elements will impact the value that can be created.

Next, to reiterate the point at the beginning of this section, it is important to realise that financial value can only be created for the firm's owner, and ultimately, therefore, only for a human being; it is not created for the firm or an aggregation of different individuals, unless there are multiple owners.

Further, many speak of firms that create value, but it is crucial to recognise that it is not a firm in and of itself which is being valued, but rather a stream of cash flows. This is because if value is not turned into cash by someone, it remains an indication of the value that could possibly be created. Remembering this, it is straightforward to appreciate that any value created is likely to deviate from, for instance, the net present value of the cash flows the firm generates (i.e. the bottom line metric of the second corporate cash flow level in Figure 1), and certainly different from any management accounting indicator like "profit". The first difference is caused by the fact that an investor always transcends the firm, and in moving between the investor and the firm, cash flows may change. For instance, as a result of additional debt attracted by a holding company that resides between the operating company (firm) and the investor, as illustrated in the topmost schema in Figure 1 i.e. Level 1 (row), relevant entities (column).

It is at the highest investment management level in Figure 1 where the ownership chain, and therefore, all cash flow investments and returns, end. At that level, all sources of value can be accessed because the owner has at least in principle, authority over all decision making levels, and therefore, overall decisions. Hence, only at this level, can the amount of value that is created be quantified.

\subsection{Identifying six sources of value creation}

In part, the suggested value management levels are discerned following a common typology of finance metrics (e.g. gross margin, EBITDA and net profit). However, as already noted, it is also important to understand how the levels relate to different "sources" of value. It is posited here that six such sources can be identified as follows (see, the final column in Figure 1, a typical source of value):

1. Autonomous revenue growth.

2. Cost reductions.

3. Balance sheet restructuring.

4. Leverage.

5. Buy and build (synergy).

6. Price/earnings (P/E) magic. 
The sixth of these sources, P/E magic, likely sounds the least familiar, even though it is very important in business practice. This particular source is different from the other sources because it is an investor-owner privilege: it relates to ownership itself. P/E magic refers to the "buy low, sell high" phenomenon that exists regardless of a firm's underlying cash flows. As an example, an investor-owner may create value in this way when other investors are willing to pay a premium for a firm because of synergies only the investors can realise. Another example would be if investors are willing to pay big money for loss making firms based on the hope of future profits or - even more magical - based on the hope that someone else will pay even more later on based on that hope of profits or based on the hope that a third investor will pay even more later on, and so on. P/E magic is the primary source of value for shareholders of internet start-ups and the only source of value for owners of firms that are loss-making. Of course, "hope" is not a strategy as it turns decision making into gambling, but $\mathrm{P} / \mathrm{E}$ magic is both real and common.

\subsection{Relating sources of value to value management levels}

3.4.1 The two revenue levels: the individual case level and the segment level. As can be seen in Figure 1, the bottom two levels are the sixth individual case level (referring to an individual sales transaction or contract) and the fifth segment level. At the individual case level, gross margin is the metric, which has the closest relation to value creation. Assuming customers actually pay for the product or service (making this assumption is necessary at this level because invoice collection occurs at a higher level), incremental gross margin when calculated without the allocation of fixed cost items - will always contribute to a higher return, and therefore, to more value[2]. In some cases, an extra-computable "net margin" might be more accurate. This would be the case if incremental operational expenses are made beyond the regular cost of goods sold (COGS) for a particular sale or transaction. These additional costs would have to be included before it is certain that value is affected positively. Even though such incremental types of expenses are usually not included in the COGS when following management accounting standards, they should be included from an information point of view. Obviously, a positive gross margin does not mean value cannot be destroyed, for instance, because of capital expenditures (CAPEX) made to secure that incremental gross margin. Logically, both OPEX and CAPEX must be included in any investment decision. Nonetheless, once invested, incremental gross margin will result in more value.

Moving on, one level up is the segment level. A segment usually refers to a specific group of customers or contracts that firms are inclined to target and service separately. The value element that is added to the lower individual case level to reach this more aggregate level are the direct costs, which, for example, cover the personnel expenses of the account managers that work exclusively for this segment (see the bottom two entries in the last column of Figure 1, calculations). Here, the implicit assumption is that the sum of gross margins within this segment must at least cover all costs that are directly incurred to generate revenues. The bottom line metric of the fifth segment level with the closest relation to the value creation calculation is the contribution margin. Although not a standard management accounting balance, it is useful as an indicator of how much excess cash a particular group of customers generates for the firm after all costs incurred exclusively for this group are taken into account. Importantly, it is at these bottom two levels where any firm's viability or lack thereof, becomes apparent because all revenues are generated at these levels. As can be seen in Figure 1, autonomous revenue growth is the only source of value that can be tapped into at these bottom two levels. Or more specifically, gross margin at the sixth level and contribution margin at the fifth level. In both cases, value results from a change in the incoming cash flow and this excess cash must come from additional revenues at these bottom two levels, not from a reduction in costs.

PAGE 700 | FORESIGHT | VOL. 21 NO. 62019 
It can be argued that all strategic thinking is ultimately done to improve the probability of generating more revenues. Autonomous revenue growth is also the only source of value a strategist cannot tap into directly because its outcome is dependent on a third party: the customer. All other sources of value are not matters of probability in this way, but matters of choice. Either the source is available or it is not, and if it is, the outcome of any decision to tap into one of these sources is known at the time of decision making. Obviously, given they are matters of choice, any sensible decision maker will try to benefit from these sources as much as possible, as soon as possible. Following this logic, it becomes clear why almost all everyday focus in business is directly or indirectly aimed at realising autonomous revenue growth.

3.4.2 The main accounting levels: the divisional level and the corporate accounting level. At the fourth divisional level, the bottom line metric relating to value creation is the familiar EBITDA. While at the third corporate accounting level the relevant metric, net profit, is even more well-known. The fourth divisional level is one step up from the segment level, thus to calculate a divisional EBITDA based on the segment level's bottom line contribution margin metric, all division-related indirect costs (not directly related to revenues) must be subtracted. In the case of a large division, this might include divisional overheads such as management, staff and possibly housing and marketing expenses.

In some cases, corporate overheads are also charged to the division. Dependent on the actual costs incurred for the division at the firm's headquarters, as well as on the level of influence the division can exert on these costs, they should or should not be included in the calculation to improve EBITDA as an indicator for what value is or could be created. In practice, EBITDA is widely used as an indicator of the cash generating capacity of a particular division or firm, for instance in the field of mergers and acquisitions. Mainly because it includes all business specific costs while leaving out (non-business specific) financing and one-time investments. The latter two elements are largely matters of choice and can, therefore, differ greatly among firms in the same industry.

The third corporate accounting level is the highest level within the accounting perspective in Figure 1. To arrive to this level from the previous divisional level, all remaining costs not already rightfully charged to the division. must be included, as well as the costs that are usually only generated at this corporate accounting level, among which there will at least be financing expenses and corporate taxes. At the fourth and third levels, two more sources of value can be tapped into besides autonomous revenue growth. They are absolute cost reductions, usually in divisional or corporate overheads; and either absolute or relative cost reductions that can be realised as a result of overlaps in activities or benefits of scale (both being synergies) following from mergers or acquisitions (the "buy and build" source of value). Much can be said on this matter, but the essence of the cash flow effects of possible synergies is assumed to be understood. At this point, it is helpful to remember that larger companies tend to use legal structures with multiple divisions operating as independent firms. Smaller firms, however, usually calculate a single EBITDA. If this is the case, the fourth and third value management levels are effectively merged.

3.4.3 The cash flow levels: the corporate cash flow level and the investment management level. Moving one step up from the corporate accounting level, a cash flow perspective of the firm becomes appropriate. Within this perspective, the second corporate cash flow level is the lower level and this is where a strategist can establish how much net cash the firm has or can generate, forgiven temporal framings. This cash amount is related directly to the value creation calculation. In fact, only two factors mediate the passing of a definitive judgment on value creation: the cash flow changes induced by the investor-owner and the time dimension that is needed to calculate the aforementioned true bottom line value creating metric, the $\mathrm{ROI}$.

In moving from net profit at the third corporate accounting level to net cash flow at the second corporate cash flow level, two steps must be taken. Step 1, net profit must be 
adjusted for the difference between costs and actual resulting outgoing cash flows and for the difference between revenues and actual resulting incoming cash flows. Step 2, nonoperating cash flows must be added because they have no nominal equivalent in the net profit calculation. These cover:

- cash flows from "financing activities", like the drawing or repayment of debt (this does not include interest payments, as these are included in the net profit calculation); and

- cash flows from "investing activities", like CAPEX or any net investments in working capital.

This procedure of adjusting net profit to calculate the actual resulting cash flow is an indirect method, as opposed to a direct method in which a cash flow balance is calculated by immediately using cash flow stream information. What remains after these adjustments are made is the amount of net cash generated by the firm as a whole in a particular period. This net cash flow of the firm is the best indicator of any value created at this level because it might be the cash flow from the firm. They are equivalent if all additional cash is actually paid out as dividends to the investor-owner, which means no earnings are retained by the firm.

The second corporate cash flow level is also the first level at which balance sheet restructurings becomes accessible as a source of value. These restructurings usually entail one-off actions aimed at freeing cash that is unnecessarily tied up in assets (e.g. by selling an obsolete stock, machinery or redundant real estate). In some cases, value can be created by means of sale and leaseback transactions that result in additional cash inflow in the short run. In other cases, it might result in changes in accounting policies that aim to improve the scoring on bank covenants, which, in turn, may lead to more favourable debt financing conditions that would have positive cash flow effects. This source of value is much more related to financial engineering and it is not an ongoing process. In fact, balance sheet restructurings are not strategic because they do not require a type of thinking that aims to reduce inherent and unavoidable uncertainties that are an intrinsic part of doing business.

The first investment management level has already been briefly discussed, as has the P/E magic source of value that is accessible at this level. There is, however, one more source of value to discuss in the context of this top value management level: leverage. Leverage encompasses the effect that debt financing of investment has on the ROI of an investorowner. In short, by attracting debt, an investor has found a co-investor that is willing to finance a certain percentage of the investment while asking a proportionally lower part of the proceeds in return. Banks, in particular, are willing to accept this position because they seek to carry a low risk (resulting from agreed upon repayments and other guarantees), but are also willing to cap their return rate from the start. The quantifiable outcome of debt financing is that the investor-owners ROI will increase, albeit on a lower absolute amount. Further, as the ROI for the investor-owner is the true measure of value creation, leverage logically qualifies as a source of value.

Naturally, debt financing can also take place at the lower corporate or divisional levels. However, from an investor's perspective, this is irrelevant as the firm's investments (cash out) do not necessarily equal the investor's investments. They differ for instance when (parts of) investments made by the firm are funded with debt that is attracted by the firm itself. Of course, firms should strive for an optimal financing structure within their boundaries as legal entities, but this type of financing does not relate to the investment on which the investor's ROI should be calculated.

Finally, after a strategist accounts for the investor-owners possible (re)financing effects on dividends paid out at the second corporate cash flow level, they then know the relevant cash flows to be used in the ROI, which equals the return on equity for the investor. More 
specifically, the investor's cash out and all incoming cash flows that relate to it need to be included. Consequently, a definitive $\mathrm{ROI}$ cannot be calculated until the relevant stream has ended. Understandably, many firms present annualised return figures. This is unavoidable, but the fundamental shortcomings of such point-in-time judgments should be clear when all of the above is considered.

\subsection{Understanding the uncertainty that requires strategic thinking}

Business decisions are characterised by a high degree of uniqueness and accordingly, it is difficult to identify every possible outcome, and even harder to establish the likelihood of each of these outcomes. This uncertainty is, however, not equal to every aspect of business. In many cases a strategist is perfectly justified in believing that certain statements are likely to be true or even that they are certain. This is an important observation as the activity of strategic thinking is aimed at reducing uncertainty.

Logically, strategists should distinguish between information relating to what is considered to be certain and information relating to what remains uncertain. There is certainly where decision outcomes are fully controllable. This applies for instance to the activities a firm performs and for the assets it owns. When this is acknowledged, it is important not to mistake the ability to control the outcome of a particular activity or asset option for having access to that activity or asset option. Put differently, if a particular activity or asset option is not available, there is also nothing to decide on.

By contrast, there is uncertainty where the outcome is not wholly controlled by decisions, but only influenced by those decisions. It is in these cases where strategists can and should use their judgment to predict the best possible outcomes based on their tacit and explicit knowledge and experience. This looking into the future should not take on the form of calculating probabilities because an uncertain situation is not characterised by risk, but a strategist can still use his or her reasoning to discern the best course to pursue when uncertainty is maximally reduced.

3.5.1 How the sources of value relate to uncertainty. In terms of the six sources of value presented in this article, only one source is a function of uncertainties from the strategist's perspective: autonomous revenue growth. Navigating these uncertainties is thus the essence of strategic thinking. There will always be some level of uncertainty in autonomous revenue growth because its outcome is never a matter of choice. Indeed, this source is effectively about margin growth because vendor's likely dictate per unit COGS beforehand. In essence, this means that the cash flows corresponding with margin amounts are the uncertain element in business. Somewhat counterintuitively, the outcomes associated with the five other sources of value do not carry the same inherent and unavoidable uncertainty. In each of those cases, there is no third party that decides on the outcome of the decisions involved, and hence, the outcome is controlled by the decision. To explain this further, these five other sources of value are discussed below from an uncertainty perspective.

3.5.1.1 Cost reductions. Given that COGS directly relates to revenues in a perfect or nearperfect one-on-one ratio, the costs involved in the "cost reductions" source of value usually refer to operating expenses. These expenses, regardless of whether they are capitalised and visible in the balance sheet or presented as cost items in the profit and loss statement, are always controlled by a firm. This control might be partly waivered, for instance when a certain level of cost uncertainty is agreed upon, but such agreements are in themselves still fully controlled by decisions. Similarly, the fact that cost overruns on investment projects might also not appear to be predictable does not mean they are uncertain from a strategic thinking point of view. This is because cost overruns either result from bad planning, bad execution or non-fixed price agreements with vendors. Bad planning is something that can be prevented, execution is something that necessarily succeeds decision making and nonfixed price agreements are in themselves matters of choice. An exception to this argument 
would be the uncertainty that results from having to budget for expenses for which no cost standards are currently available. It could be argued that these expenses such as investments in research and development are inherently and unavoidably uncertain. Although this is technically true, it does not mean that such investments should be seen as uncertain from a strategic thinking point of view. This conclusion is based on the following line of reasoning. First of all, the proceeds from investments are naturally uncertain and accordingly, they reflect the autonomous revenue growth source of value. The costs that precede the proceeds, however, are not uncertain within the context of strategic thinking because they constitute money spent on either assets or activities and such procurements are controlled by management at the time of decision making. Possible earlier approval of a lower budget does not change the fact that there is no uncontrolled third party or randomness involved in the outcome of the decision: when the actual decision is made to pay someone for something, there is no uncertainty involved. It might seem implausible, but from a strategic thinking perspective, costs do not incorporate inherent uncertainty in the way revenues do.

3.5.1.2 Balance sheet restructurings and leverage. The source of value offered by balance sheet restructurings is independent of firm-specific contexts and can be tapped into in particular asset situations. What is involved carries no inherent uncertainty, mainly because such restructurings concern financial transactions whose implications are exhaustively covered by explicit agreements. This is also the case for leverage, even though an interest rate, and therefore, interest payments - could possibly be uncertain. However, this type of uncertainty can be hedged and it cannot be refined through incisive strategic thinking.

3.5.1.3 Buy and build and price/earnings magic. The buy and build source of value relates to synergies following from combining activities and assets. Synergies can refer to expected additional revenues, although they tend to refer to expected cost savings. In both cases the benefits are non-autonomous, and therefore, different from the benefits of the similar autonomous revenue growth and cost reduction sources of value. In terms of mergers and acquisitions, value is created when the proceeds from synergies outweigh the one-off expenses incurred to realise mergers or takeovers. Here too, the act of acquiring or merging is not dependent on a third party, but the result of a deliberate, explicit agreement. Why this source carries no inherent and unavoidable uncertainty is best explained by recognising it effectively amounts to managing multiple firms, where each firm carries a separate autonomous revenue growth uncertainty, but no obvious additional uncertainty as a result of the combination, other than the aforementioned cost overruns that result from bad planning or bad execution.

Finally, creating value by tapping into the P/E magic source of value is neither a matter of deliberate choice nor dependent on others. It relates to the use of a risk-free value creating option that simply arises or not.

3.5.2 Strategic thinking to navigate incoming cash flow uncertainties. Based on the above it is concluded that all strategic thinking should be aimed at reducing the long-term uncertainty that is an inherent and unavoidable part of autonomous revenue growth. This particular uncertainty is a composite of three identifiable uncertainties that - when combined - capture the overall uncertainty in future incoming cash flows that warrants strategic thinking efforts. These three uncertainties are as follows:

1. uncertainty relating to the timing of incoming cash flows (earlier/later);

2. uncertainty relating to the level of incoming cash flows (higher/lower); and

3. uncertainty relating to the number of incoming cash flows (more/fewer).

All three of these uncertainties impact the overall future incoming cash flow stream as illustrated in Figure 2. In this example, two investment years (black columns) precede incoming cash flows. The upper two graphs illustrate the cash flow estimates in the annual 


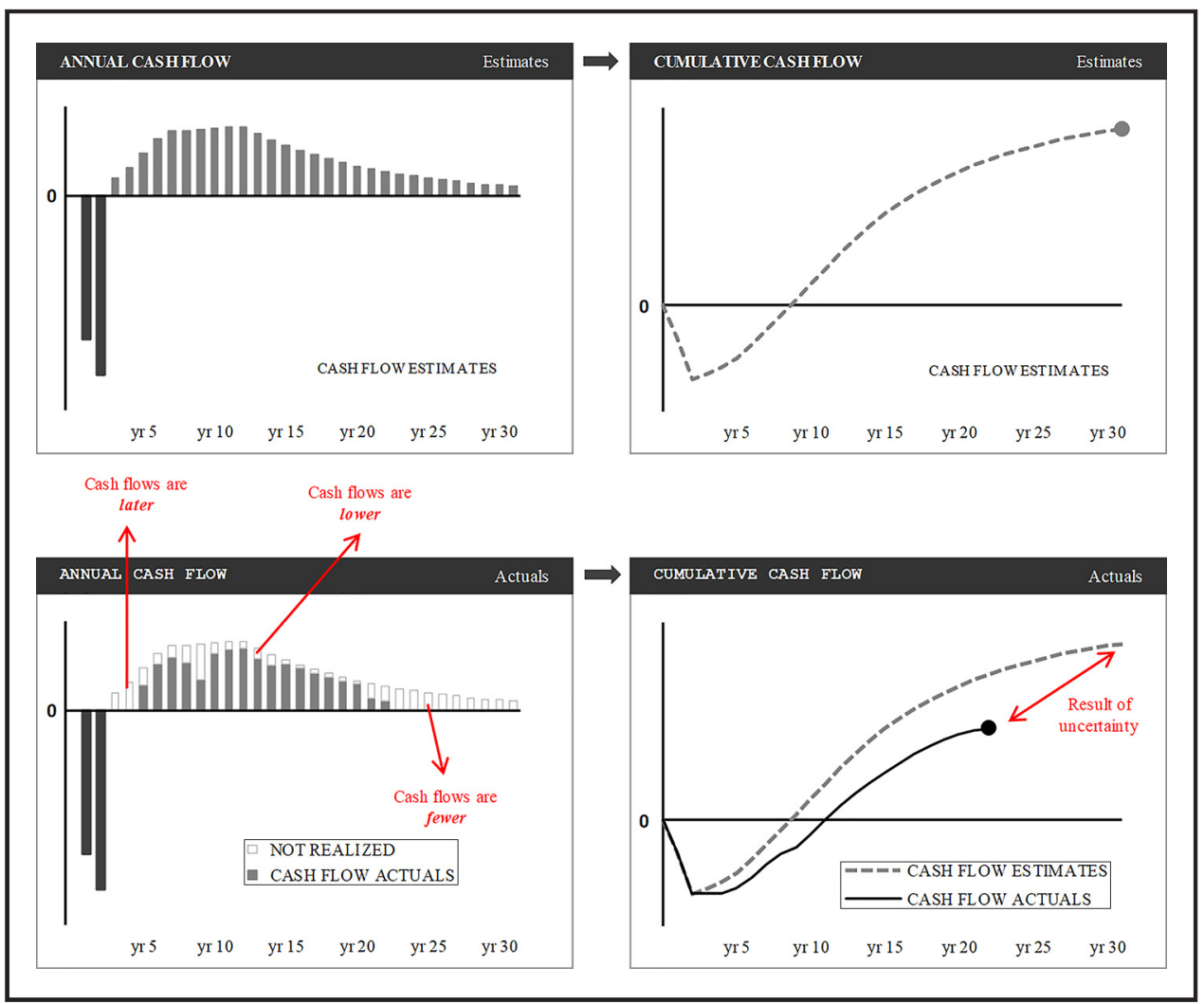

(left graph) and cumulative (right graph) terms. The lower graphs show the extent to which such estimates might turn out differently if they are negatively impacted in all three uncertainty respects. The bottom right graph shows how the combined uncertainty would change the cumulative cash flow stream, and thus, change the extent to which value is actually created.

\section{Summary and conclusions}

Strategic decision making needs to go beyond the gathering of information and having a vague notion of value creation. Demonstrating wisdom requires - as a minimum - thorough knowledge of how value creation works, how it is measured and what sources of value exist. This article explores this by showing how decision making may take place at any of six different management levels. More sources of value become available at higher levels, but only one source of value demands true strategic thinking. This source of value is autonomous revenue growth and it can be tapped into at any decision making level. As such, demonstrating strategic wisdom is possible for anyone within a firm and ultimately, it resolves down to the thinking and decision making that increases the chances of generating higher, earlier and more future incoming cash flows. In practical terms, this requires careful documentation and operationalisation of the roles and responsibilities of personnel within firms so that cash flows are appropriately understood and leveraged. Bespoke management systems are key in this respect (Perrott, 2011).

There is ample scope for future research in this domain in terms of empirical applications and evaluations. This includes understanding how the framework can be incorporated in 
scenario planning exercises (Hirsch et al., 2013) pursuant to identifying plausible and viable business development opportunities.

\section{Notes}

1. Uncertainty does not equal risk. They differ in terms of the extent to which the number, magnitude and likelihood of outcomes can be confidently quantified. Risk is associated with chance and salient studies in this domain include Agarwal and Ansell (2016), Beasley et al., (2007) and Elahi (2013). Beyond chance, business decisions are characterised by a high degree of uniqueness. Accordingly, it is hard to identify every possible outcome and even harder to establish the likelihood of each outcome. This is uncertainty.

2. The same cannot be said about incremental revenues as value can be destroyed even when revenues increase. This will always happen when products are sold below COGS. Clearly, this would also result in a negative gross margin.

\section{References}

Adams, T.E. (2017), "Autoethnographic responsibilities", International Review of Qualitative Research, Vol. 10 No. 1, pp. 62-66.

Anbarci, N. and Feltovich, N. (2017), "Pricing in competitive search markets: the roles of price information and fairness perceptions", Management Science, Vol. 64 No. 3, pp. 1101-1120.

Agarwal, R. and Ansell, J. (2016), "Strategic change in enterprise risk management", Strategic Change, Vol. 25 No. 4, pp. 427-439.

Beasley, M.S., Frigo, M.L. and Litman, J. (2007), "Strategic risk management: creating and protecting value", Strategic Finance, Vol. 88 No. 11, pp. 24-31.

Bettis, R.A. and Prahalad, C.K. (1995), "The dominant logic: Retrospective and extension", Strategic Management Journal, Vol. 16 No. 1, pp. 5-14.

Boland, L.A. (1981), "On the futility of criticizing the neoclassical maximization hypothesis", The American Economic Review, Vol. 71 No. 5, pp. 1031-1036.

Cosenz, F. and Noto, G. (2016), "Applying system dynamics modelling to strategic management: a literature review", Systems Research and Behavioral Science, Vol. 33 No. 6, pp. 703-741.

Doloriert, C. and Sambrook, S. (2011), "Accommodating an autoethnographic PhD: the tale of the thesis, the viva voce, and the traditional business school”, Journal of Contemporary Ethnography, Vol. 40 No. 5, pp. 582-615.

Durand, R. and Vaara, E. (2009), "Causation, counterfactuals, and competitive advantage", Strategic Management Journal, Vol. 30 No. 12, pp. 1245-1264.

Elahi, E. (2013), "Risk management: the next source of competitive advantage", Foresight, Vol. 15 No. 2 , pp. 117-131.

Fowler, A. (2003), "Systems modelling, simulation, and the dynamics of strategy", Journal of Business Research, Vol. 56 No. 2, pp. 135-144.

Hirsch, S., Burggraf, P. and Daheim, C. (2013), "Scenario planning with integrated quantification-managing uncertainty in corporate strategy building", Foresight, Vol. 15 No. 5, pp. 363-374.

Jarzabkowski, P., Kaplan, S., Seidl, D. and Whittington, R. (2016), "If you aren"t talking about practices, don't call it a practice-based view: rejoinder to Bromiley and Rau in strategic organization", Strategic Organization, Vol. 14 No. 3, pp. 270-274.

Kempster, S. and Stewart, J. (2010), "Becoming a leader: a co-produced autoethnographic exploration of situated learning of leadership practice", Management Learning, Vol. 41 No. 2, pp. 205-219.

Kim, H., Park, K. and Ryu, D. (2017), "Corporate environmental responsibility: a legal origins perspective", Journal of Business Ethics, Vol. 140 No. 3, pp. 381-402.

Kline, P. and Moretti, E. (2014), "People, places, and public policy: some simple welfare economics of local economic development programs", Annual Review of Economics, Vol. 6 No. 1, pp. 629-662. 
Kydland, F.E. and Prescott, E.C. (1977), "Rules rather than discretion: the inconsistency of optimal plans", Journal of Political Economy, Vol. 85 No. 3, pp. 473-491.

Lah, M., Sušjan, A. and Redek, T. (2016), "Corporate communication and economic theory: an institutionalist perspective", Journal of Economic Issues, Vol. 50 No. 1, pp. 121-144.

Lather, P. (1986), "Research as praxis", Harvard Educational Review, Vol. 56 No. 3, pp. 257-278.

Liedtka, J.M. (1998), "Strategic thinking: can it be taught?", Long Range Planning, Vol. 31 No. 1, pp. $120-129$.

Liu, W., Sharp, J. and Wu, Z. (2006), "Preference, production and performance in data envelopment analysis", Annals of Operations Research, Vol. 145 No. 1, pp. 105-127.

Mantere, S. (2013), "What is organizational strategy? A language-based view", Journal of Management Studies, Vol. 50 No. 8, pp. 1408-1426.

Perrott, B.E. (2011), "Strategic issue management as change catalyst", Strategy \& Leadership, Vol. 39 No. 5, pp. 20-29.

Piron, R. and Fernandez, L. (1995), "Are fairness constraints on profit-seeking important?", Journal of Economic Psychology, Vol. 16 No. 1, pp. 73-96.

Porter, M.E. (1989), "How competitive forces shape strategy", in Bowman, C. and Asch, D.C. (Eds), Readings in Strategic Management, Macmillan, Hampshire, pp. 133-143.

Porter, M.E. (2008), "The five competitive forces that shape strategy", Harvard Business Review, Vol. 86 No. 1, pp. 25-40.

Schön, D.A. (1991), The Reflective Practitioner, Ashgate Publishing, Farnham.

Van Zanten, J.A. and Van Tulder, R. (2018), "Multinational enterprises and the sustainable development goals: an institutional approach to corporate engagement", Journal of International Business Policy, Vol. 1 Nos 3/4, pp. 208-233.

\section{Corresponding author}

Roeland van Straten can be contacted at: vanstraten@seyst.nl

For instructions on how to order reprints of this article, please visit our website: www.emeraldgrouppublishing.com/licensing/reprints.htm

Or contact us for further details: permissions@emeraldinsight.com 